Sains Malaysiana 47(3)(2018): 543-549

http://dx.doi.org/10.17576/jsm-2018-4703-15

\title{
Infeksi Mycobacterium tuberculosis: Data Demografi dan Perbandingan \\ Ujian Kerentanan Anti-Tuberkulosis
}

(Mycobacterium tuberculosis Infection: Demographic Data and Comparison

of Anti-Tuberculosis Susceptibility Test)

\author{
NORAZIAH MOHAMAD ZIN*, AlFIZAH HANAFIAH \& NUR HidAYAH MASOD
}

\begin{abstract}
ABSTRAK
Tuberkulosis merupakan masalah utama dalam kesihatan awam di kebanyakan negara membangun termasuklah Malaysia. Di Malaysia, bilangan kes kematian disebabkan tuberkulosis menurun tetapi yang membimbangkan adalah apabila terdapat peningkatan kes kerintangan Mycobacterium tuberculosis terhadap ubat-ubatan sedia ada. Dalam kajian ini, data demografik pesakit telah dianalisis dan kerintangan M. tuberculosis terhadap agen anti-tuberkulosis (Isoniazid, Streptomycin, Rifampicin dan Ethambutol) telah dikenal pasti dengan menggunakan ujian kerentanan plat MYCOTB. Sejumlah 40 pencilan klinikal M. tuberculosis yang dipencil daripada pesakit di PPUKM telah dipilih secara rawak. Dalam kalangan pesakit tuberkulosis, seramai 62.5\% adalah lelaki (purata umur: $36.9 \pm 17.9$ tahun) manakala $37.5 \%$ adalah wanita (purata umur: 42.6+16.6 tahun). Pesakit berbangsa Melayu mencatatkan peratusan tertinggi iaitu 60\%, diikuti pesakit India 15\%, Cina 5\% dan lain-lain bangsa 20\%. Pemencilan M. tuberculosis daripada sampel klinikal adalah masing-masing 60\%, 17.5\%, 7.5\%, 7.5\%, 5\% dan 2.5\% daripada kahak, aspirat trakea, nanah, darah, larvaj bronkoalveolar dan tisu. Ini berhubung kait dengan pesakit Tuberculosis yang majoritinya (67.5\%) hadir dengan simptom batuk berpanjangan. Keputusan ujian kerentanan antara MYCOTB dan BACTECMGIT 960 telah dibandingkan. Purata masa yang diperlukan untuk ujian kerentanan anti-TB menggunakan plat MYCOTB dan BACTEC MGIT 960 ialah masing-masing 2 dan 40.5 minit. Kos setiap sampel bagi plat MYСОTB dan BACTEC MGIT 960 adalah masing-masing RM16.65 dan RM42.87. Sebagai kesimpulan, berdasarkan data demografik, jangkitan TB dalam kalangan pesakit lelaki kaum Melayu adalah yang tertinggi sementara kahak merupakan spesimen yang paling banyak diterima. Penggunaan plat MYCOTB adalah lebih baik berbanding BACTEC MGIT 960 dan keputusan ujian kerentanan menunjukkan pencilan klinikal tersebut adalah 100\% rentan kepada agen anti-TB yang diuji. Data yang diperoleh boleh digunakan sebagai maklumat dalam pengemaskinian panduan diagnosis dan rawatan TB pada masa hadapan.
\end{abstract}

Kata kunci: BACTEC MGIT 960; Mycobacterium tuberculosis; plat MYCOTB; tuberkulosis

\section{ABSTRACT}

Tuberculosis (TB) is a major health problem in many developing countries including Malaysia. In Malaysia, the number of death due to tuberculosis has decreased, but there is rising concern on the increase of drug resistance (multi drug resistance tuberculosis) cases. In this study, patients' demographic data were analyzed and the susceptibility of Mycobacterium tuberculosis against anti-tuberculosis agents (isoniazid, streptomycin, rifampicin and ethambutol) was determined using susceptibility МҮСОтВ plates. A total of 40 clinical M. tuberculosis isolates, isolated from patients in PPUKM were randomly selected. Among these, 62.5\% were male (mean age: $36.9 \pm 17.9$ years) and $37.5 \%$ were female (mean age: $42.6 \pm 16.6$ years). Malay patients accounted for the highest percentage of TB cases which was $60 \%$, followed by Indians $15 \%$, 5\% Chinese and $20 \%$ other ethnics. The isolation of M. tuberculosis from clinical samples were $60 \%$, $17.5 \%, 7.5 \%, 7.5 \%, 5 \%$ and $2.5 \%$ from sputum, tracheal aspirate, pus, blood, BAL and tissue, respectively. This is correlated with the majority of the patients (67.5\%) infected with $\mathrm{M}$. tuberculosis having persistent cough symptoms. The results from MYСОTВ and BACTEC MGIT 960 susceptibility testing were compared. The average time taken to do the anti-TB susceptibility test by using MYCOTB plate and BACTEC MGIT 960 was 2 and 40.5 min, respectively. Cost per sample for MYСОTВ and BACTEC MGIT 960 was RM16.65 and RM42.80, respectively. To conclude, based on our demographic data, TB infection was the highest amongst male Malay patients and the main specimens that been received was sputum sample. MYСОTB plate was more preferable than BACTEC MGIT 960 for the susceptibility testing and all clinical samples were $100 \%$ susceptible to all tested anti-TB agents. Data gathered from this study can be used as guideline for the management of TB diagnosis and treatment in the future.

Keywords: BACTEC MGIT 960; Mycobacterium tuberculosis; MYCOTB plate; tuberculosis 


\section{Pengenalan}

Mycobacterium tuberculosis (M. tuberculosis) adalah bakteria bawaan titisan udara, berdiameter 1-5 mikron dan menyebabkan penyakit tibi. Titisan udara boleh dicemari apabila pesakit tibi pulmonari batuk, bersin, menjerit atau menyanyi (CDC 2013). Seseorang boleh dijangkiti M. tuberculosis sekiranya menyedut masuk titisan udara yang tercemar dengan $M$. tuberculosis ke dalam saluran pernafasan dan seterusnya bermigrasi ke paru-paru. Di alveoli paru-paru, sel bakteria akan dikelilingi dan ditelan oleh sel imuniti perumah yang dikenali sebagai makrofaj. Walau bagaimanapun, bakteria ini boleh menghalang tindakan fagosom seterusnya untuk membiak di dalam sel tersebut (Russel 2011). Walau bagaimanapun, sesetengah sel bakteria yang ditelan oleh makrofaj akan dipersembahkan pada sel darah putih seterusnya akan merangsang sistem imun dengan lebih banyak sel-sel bakteria akan ditelan dan membentuk granuloma. Pada waktu ini tuberculosis dorman akan berlaku (CDC 2013).

Pada tahun 2001, tuberkulosis merupakan penyakit berjangkit kedua yang paling kerap dicatatkan di Malaysia (Dony et al. 2004). Jangkitan tuberkulosis dapat dikategorikan kepada tiga jenis iaitu tuberkulosis pulmonari, tuberkulosis ekstrapulmonari dan tuberkulosis miliari (WHO 1974). Satu kajian lepas mendapati $83 \%$ pesakit tibi menghidapi jangkitan tuberkulosis pulmonari (Nantha 2014). Kajian retrospektif yang telah dijalankan di Hospital Kuala Lumpur pada tahun 2001 mendapati kebanyakan pesakit HIV di institusi kesihatan tersebut mengalami jangkitan tuberkulosis pulmonari (Nissapatorn et al. 2001). Pesakit jangkitan tuberkulosis pulmonari biasanya menunjukkan simptom batuk dan X-ray dada yang abnormal.

Pada tahun 2013, bilangan kes baru tibi tertinggi dicatatkan berlaku di negara-negara Asia Tenggara (CDC 2013). Antara negara Asia Tenggara, Singapura mencatatkan kadar kejadian terendah iaitu 47 kadar kejadian setiap 100,000 penduduk diikuti oleh Brunei 58 kadar kejadian setiap 100,000 penduduk dan Malaysia 99 kadar kejadian setiap 100,000 penduduk. Cambodia mencatatkan kadar kejadian tertinggi dengan 400 kadar kejadian setiap 100,000 penduduk. Beberapa faktor telah dikaitkan dengan pertambahan bilangan pesakit tibi, antaranya, kemiskinan, kekurangan penjagaan dan kemudahan perubatan dan persekitaran serta gaya hidup yang tidak sihat (Waaler 2002). Kajian ini bertujuan untuk memberikan gambaran terkini jangkitan tibi dalam kalangan pesakit di Pusat Perubatan Universiti Kebangsaan Malaysia (PPUKM). Di samping itu, ia dapat membantu pihak makmal mengembangkan teknik diagnostik bagi ujian kerentanan jangkitan TB yang boleh meningkatkan mutu rawatan pesakit.

\section{METOD}

\section{REKA BENTUK KAJIAN}

Data demografik daripada rekod klinikal pesakit telah dianalisis. Kelulusan etika untuk menjalankan penyelidikan adalah di bawah kod NN012302014. Di samping itu, ujian kerentanan anti-TB ke atas pencilan klinikal M. tuberculosis ditentukan dengan menggunakan kaedah plat MYCOTB dan keputusan dibandingkan dengan keputusan daripada BACTEC MGIT 960.

\section{DATA DEMOGRAFIK DAN KLINIKAL PESAKIT}

Dalam kajian ini terdapat dua jenis data yang diperoleh iaitu data primer dan data sekunder. Data primer merupakan sumber data yang diperoleh secara langsung daripada keputusan kajian yang dijalankan. Data sekunder merupakan sumber data penelitian yang diperoleh secara tidak langsung melalui media perantara. Dalam kajian ini data primer merujuk kepada keputusan ujian kerentanan yang dijalankan menggunakan plat МYСОТВ. Manakala data sekunder merujuk kepada data demografik dan klinikal pesakit yang diperoleh daripada simpanan rekod di Makmal Bakteriologi, PPUKM. Data demografik dan klinikal yang dianalisis adalah umur, jantina, bangsa, jenis spesimen dan diagnosis klinikal pesakit.

Di samping itu, data sekunder juga merujuk kepada data yang dikumpul daripada ujian kerentanan yang dijalankan dengan sistem BACTEC MGIT 960 di PPUKM sepanjang tempoh kajian. Data ini melibatkan keputusan kerentanan pencilan terhadap empat jenis agen anti-TB iaitu Streptomicin, Isoniazid, Rifampicin dan Ethambutol.

\section{PERSAMPELAN}

Populasi kajian hanya melibatkan pencilan klinikal yang telah dikenal pasti sebagai $M$. tuberculosis melalui kaedah konvensional mikrobiologi. Sebanyak 40 pencilan $M$. tuberculosis yang dipencil pada bulan Ogos 2013 hingga Oktober 2013 telah dipilih secara rawak sebagai sampel dalam kajian ini. Penentuan saiz sampel bagi kajian adalah berdasarkan kaedah penentuan saiz sampel oleh Krejcie dan Morgan (1970). Berdasarkan kaedah tersebut saiz sampel sebanyak 40 berpadanan dengan saiz populasi kajian.

\section{UJIAN KERENTANAN DENGAN KAEDAH PLAT MYCOTB}

Dua hingga tiga koloni tunggal dilarutkan ke dalam 5 $\mathrm{mL}$ air suling steril yang mengandungi lima biji manik kaca steril. Campuran divorteks selama $30 \mathrm{~s}$. Larutan dibiarkan selama $15 \mathrm{~min}$ bagi memendakkan sel terampai. Supernatan dipipet keluar dan dimasukkan ke dalam tiub tabung uji yang steril. Kekeruhan inokulum disesuaikan dengan kekeruhan piawai 0.5 McFarland. Sejumlah 100 $\mu \mathrm{L}$ larutan inokulum dipipet masuk ke dalam tiub yang mengandungi kaldu Middlebrook 7H9 dan oleic acidalbumin dextrose-catalase (OADC) bagi menyediakan kepekatan akhir inokulum sebanyak $1 \times 10^{5} \mathrm{cfu} / \mathrm{mL}$ (julat yang diterima pakai adalah $5 \times 10^{4}$ hingga $5 \times 10^{5} \mathrm{cfu} / \mathrm{mL}$ ). Campuran divorteks selama $30 \mathrm{~s}$. Seterusnya sebanyak 100 $\mu \mathrm{L}$ inokulum dipipet masuk ke dalam setiap telaga pada plat МҮСОтв. Sampel kemudian diinkubasi selama tujuh hingga sepuluh hari dalam inkubator bersuhu $35-37^{\circ} \mathrm{C}$ 
dengan kehadiran 5\% $\mathrm{CO}_{2}$. Keputusan dicerap melalui pemerhatian berbentuk butang bagi setiap telaga. Bentuk butang yang terbentuk pada telaga paling awal bagi satusatu jenis agen anti-TB mewakili nilai minimum kepekatan anti-TB yang diperlukan bagi merencatkan pertumbuhan (MIC).

\section{KEPUTUSAN KAJIAN}

\section{DATA DEMOGRAFIK PESAKIT}

Hasil analisis data demografik pesakit didapati bilangan pesakit lelaki adalah lebih tinggi $(62.5 \%)$ berbanding pesakit wanita (37.5\%). Pesakit berbangsa Melayu mencatatkan jumlah peratusan tertinggi iaitu $60 \%$, diikuti lain-lain bangsa 20\%, Cina 15\% manakala India hanya 5\%. Lain-lain bangsa mewakili suku kaum Sabah dan Sarawak seperti Bidayuh dan Kadazan.

Dalam kajian ini terdapat empat kumpulan julat usia iaitu, berusia 0 hingga 19 tahun (kumpulan I), 20 hingga 39 tahun (kumpulan II), 40 hingga 59 tahun (kumpulan III) manakala 60 hingga 79 tahun (kumpulan IV). Hasil analisis mendapati kumpulan II dan kumpulan III mencatatkan kekerapan tertinggi iaitu 35\% setiap satunya. Kumpulan pesakit dalam julat usia 0 hingga 19 tahun dan 60 hingga 79 tahun masing-masing mencatatkan 15\%. Ringkasan demografik ini dapat dilihat pada Jadual 1.

JADUAL 1. Ringkasan demografi pesakit

\begin{tabular}{cccc}
\hline \multirow{2}{c}{ Variabal } & $\begin{array}{c}\text { Frekuensi } \\
(n=40)\end{array}$ & Peratus (\%) \\
\hline \multirow{2}{*}{ Jantina } & Lelaki & 25 & 62.5 \\
& Perempuan & 15 & 37.5 \\
& Melayu & 24 & 60 \\
Bangsa & Cina & 6 & 5 \\
& India & 2 & 15 \\
& Lain-lain & 8 & 20 \\
& $0-19$ & 6 & 15 \\
Usia & $20-39$ & 14 & 35 \\
& $40-59$ & 14 & 35 \\
& $60-79$ & 6 & 15 \\
\hline
\end{tabular}

\section{DIAGNOSIS KLINIKAL DAN JENIS SPESIMEN}

Rajah 1 menunjukkan bilangan pesakit berdasarkan jenis diagnosis klinikal yang telah dikenal pasti oleh pegawai perubatan ketika melakukan pemeriksaan terhadap pesakit. Seramai 27 orang pesakit menunjukkan simptom batuk berpanjangan melebihi dua minggu diikuti simptom lain seperti demam dan pengurangan berat badan. Seramai tiga orang pesakit HIV didapati positif dengan jangkitan tibi. Seramai empat orang pesakit yang disyaki menghidapi tibi meningitis manakala dua orang pesakit masing-masing didiagnos dengan limfadenitis, miliari dan tibi berulang.

Rajah 2 menunjukkan jenis dan bilangan spesimen klinikal yang diterima. Sampel sputum mencatatkan nilai tertinggi iaitu sebanyak 24 sampel, diikuti tujuh sampel aspirat trakea, tiga sampel darah, tiga sampel nanah dan dua sampel lavaj bronkoalveolar (BAL) manakala hanya satu sampel tisu diterima. Jenis-jenis sampel diambil berdasarkan diagnosis klinikal yang dilakukan oleh pegawai perubatan sewaktu pemeriksaan.

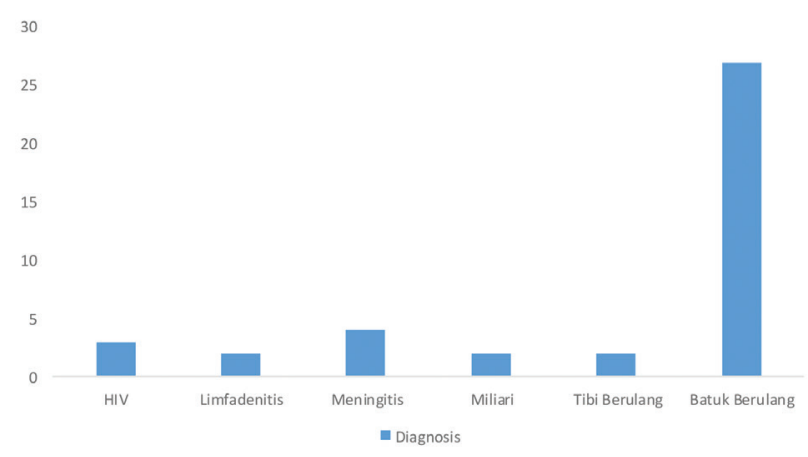

RAJAH 1. Carta bar menunjukkan bilangan pesakit berdasarkan diagnosis klinikal

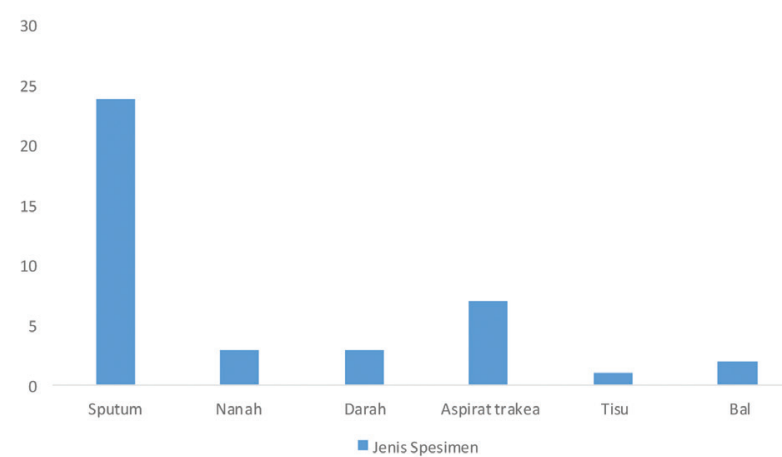

RAJAH 2. Carta bar menunjukan jenis dan bilangan spesimen klinikal yang diterima

UJIAN KERENTANAN ANTI-TB MENGGUNAKAN SISTEM BACTEC MGIT 960 DAN PLAT MYCOTB

Jadual 2 menunjukkan perbandingan kepekatan anti-TB yang digunakan dalam ujian kerentanan menggunakan sistem BACTEC MGIT 960 dan kaedah plat MYCOTB. Ujian kerentanan menggunakan sistem BACTEC MGIT 960 hanya menggunakan satu kepekatan anti-TB iaitu Isoniazid 0.1 $\mu \mathrm{g} / \mathrm{mL}$, Streptomycin $1.0 \mu \mathrm{g} / \mathrm{mL}$, Rifampicin $1.0 \mu \mathrm{g} / \mathrm{mL}$ dan Ethambutol $5.0 \mu \mathrm{g} / \mathrm{mL}$. Berbeza dengan BACTEC MGIT 960, kaedah plat MYСОТВ menggunakan beberapa nilai kepekatan anti-TB yang diuji. Julat kepekatan anti-TB bagi Streptomycin adalah $0.25-32 \mu \mathrm{g} / \mathrm{mL}$, Isoniazid 0.03-4.0 $\mu \mathrm{g} / \mathrm{mL}$, Rifampicin $0.12-16.0 \mu \mathrm{g} / \mathrm{mL}$ dan Ethambutol 0.3-4.0 $\mu \mathrm{g} / \mathrm{mL}$.

Jadual 3 merumuskan keputusan ujian dengan kaedah plat MYCOTB. Bagi bahan antimikrob Streptomyicin, sebanyak 25 pencilan mencatatkan nilai MIC $<0.25 \mu \mathrm{g} /$ $\mathrm{mL}, 23$ pencilan mencatatkan nilai MIC $0.25 \mu \mathrm{g} / \mathrm{mL}$ dan 24 sampel mencatatkan nilai MIC $1.0 \mu \mathrm{g} / \mathrm{mL}$. Bagi bahan antimikrob isoniazid, sebanyak 27 sampel mencatatkan MIC $<0.03 \mu \mathrm{g} / \mathrm{mL}$ dan 13 sampel mencatatkan nilai MIC 
JADUAL 2. Senarai kos produk dan reagen bagi plat MYCOTB

\begin{tabular}{cccc}
\hline Produk & Unit (kuantiti) & Kos per unit (RM) & Kos per ujian (RM) \\
\hline Plat MYCOTB & 12 antimikrob / plat & 157.5 & 13.14 \\
Medium middlebrook 7H9 dan OADC & 100 unit/kotak & 351 & 3.51 \\
& & Jumlah kos per ujian & 16.65 \\
\hline
\end{tabular}

JADUAL 3. Senarai kos produk dan reagen bagi BACTEC MGIT 960

\begin{tabular}{cccc}
\hline Produk & Unit (kuantiti) & Kos per unit (RM) & Kos per ujian (RM) \\
\hline Inkubator BACTEC MGIT 960 & 1 & 120,000 & 7.8 \\
Tiub MGIT & 100 unit/kotak & 780 & 8.09 \\
Medium pengkaya S.I.R.E & 35 unit/kotak & 283.2 & 6.66 \\
Medium middlebrook 7H9 dan OADC & 25 unit/kotak & 166.5 & 20.32 \\
Bahan antimikrob & 25 unit/ kotak & 508 & 42.87 \\
\hline
\end{tabular}

$0.06 \mu \mathrm{g} / \mathrm{mL}$. Bagi ethambutol, 1 sampel mencatatkan MIC $0.3 \mu \mathrm{g} / \mathrm{mL}$ dan sebanyak 39 sampel mencatatkan nilai MIC $1.2 \mu \mathrm{g} / \mathrm{mL}$. Bagi rifampicin kesemua sampel menunjukkan nilai $\mathrm{MIC}<0.12 \mu \mathrm{g} / \mathrm{mL}$.

Jadual 4 menunjukkan keputusan ujian kerentanan dengan menggunakan kaedah plat MYCOTB dan sistem BACTEC MGIT 960. Kesemua pencilan (100\%) adalah rentan terhadap Streptomycin, Isoniazid, Ethambutol dan Rifampicin apabila diuji dengan kaedah MYСОтв.

\section{PERBINCANGAN}

Data demografik yang dianalisis mendapati min usia tertinggi dijangkiti tuberkulosis adalah 39.5 tahun. Pemerhatian yang hampir sana diperoleh dalam satu kajian yang dilakukan di Kelantan yang mendapati min usia jangkitan tuberkulosis adalah 45 tahun (Nik et al. 2001). Laporan yang dikeluarkan oleh Kementerian Kesihatan Malaysia pada tahun 2000 mendapati 75\% kes tibi melibatkan kumpulan yang produktif iaitu 20 hingga 54 tahun (KKM 2000).

Terdapat beberapa faktor seperti gaya hidup dan status kesihatan boleh meningkatkan risiko jangkitan tuberkulosis. Kedua-dua lelaki dan wanita adalah berisiko dijangkiti. Kajian terdahulu mendapati, jangkitan tibi pada pesakit lelaki melebihi pesakit wanita (KKM 2013; Mokhtar et al. 2012). Dianggarkan dua pertiga kes notifikasi tibi yang dilaporkan kepada WHO adalah lelaki manakala hanya satu pertiga sahaja adalah wanita (Netto et al. 1998).
Pemerhatian yang sama diperoleh dalam kajian ini dengan $62.5 \%$ adalah pesakit lelaki manakala $37.5 \%$ adalah pesakit wanita. Perkara ini mungkin dipengaruhi oleh gaya hidup dan keperluan pekerjaan kaum lelaki yang bekerja di luar dan kekerapan bercampur dengan masyarakat yang dapat meningkatkan risiko jangkitan. Satu kajian yang dilakukan di Sarawak pada 2006, mendapati pesakit wanita lewat hadir ke institusi kesihatan untuk menerima rawatan berbanding pesakit lelaki (Chang \& Esterman 2007), yang dipengaruhi oleh gaya hidup mereka dan kebergantungan kaum wanita di Sarawak pada kaum lelaki untuk bergerak dari satu tempat ke satu tempat seterusnya menyukarkan mereka mendapatkan rawatan. Namun begitu, kajian kes yang dijalankan di Penang mendapati pesakit lelaki lewat menerima rawatan berbanding pesakit wanita disebabkan oleh faktor tahap pendidikan yang rendah (Hooi 1994).

Pemerhatian mendapati pesakit berbangsa Melayu mendominasi jangkitan iaitu sebanyak $60 \%$ berbanding dengan bangsa-bangsa lain. Ini dapat dikaitkan dengan jumlah penduduk negeri Selangor dan Wilayah Persekutuan yang majoritinya adalah berbangsa Melayu. Menurut bancian penduduk dan perumahan 2010 yang dilakukan oleh Jabatan Statistik Negara mendapati seramai 50.1\% $(2,754,826)$ penduduk Selangor dan Wilayah Persekutuan Kuala Lumpur adalah berbangsa Melayu (Jabatan Statistik Malaysia 2010).

Pemerhatian kajian yang dijalankan mendapati pesakit tuberkulosis yang disahkan penghidap HIV adalah berusia 41 hingga 46 tahun. Keadaan ini sedikit berbeza dengan

JADUAL 4. Nilai kepekatan antimikrob yang digunakan bagi BACTEC MGIT 960 dan plat MYCOTB

\begin{tabular}{ccc}
\hline Agen antimikrob & $\begin{array}{c}\text { Kepekatan antimikrob Bactec MGIT } \\
960(\mu \mathrm{g} / \mathrm{mL})\end{array}$ & $\begin{array}{c}\text { Julat kepekatan antimikrob plat } \\
\text { MYCOTB }(\mu \mathrm{g} / \mathrm{mL})\end{array}$ \\
\hline Streptomycin & 1 & $0.25-32$ \\
Isoniazid & 0.1 & $0.03-4.0$ \\
Rifampicin & 1 & $0.12-16.0$ \\
Ethambutol & 5 & $0.3-4.0$ \\
\hline
\end{tabular}


satu kajian yang yang dilakukan oleh Nantha (2014) di Klinik Kesihatan Seremban mendapati pesakit yang dijangkiti tuberkulosis dan penghidap HIV adalah berusia 29 hingga 73 tahun. Julat usia yang lebih besar mungkin dipengaruhi oleh saiz sampel yang juga lebih besar dalam kajian beliau.

Melalui teknik plat MYСОтВ, nilai MIC yang diberikan dapat memberikan gambaran nilai kepekatan anti-TB yang diperlukan untuk merencat pertumbuhan bakteria M. tuberculosis. Maklumat ini dapat dijadikan panduan dalam perawatan pesakit terutamanya apabila pesakit didapati tidak menunjukkan tindak balas positif selepas tempoh rawatan selesai. Sebarang kelewatan rawatan dapat dielakkan dan secara tindak langsung ia dapat membendung pembentukan MDR-TB pada masa hadapan. Walau bagaimanapun, sehingga kajian dijalankan tiada sebarang kerintangan terhadap bahan antimikrob secara in vitro diperoleh.

Seramai $67.5 \%$ pesakit yang hadir adalah dengan simptom batuk berpanjangan melebihi 2 minggu. Manakala jenis spesimen tertinggi adalah kahak iaitu sebanyak $60 \%$. Diikuti pula dengan spesimen aspirat trakea sebanyak $17.5 \%$. Pemerhatian ini adalah selari dengan satu kajian yang dijalankan terhadap 425 pesakit tibi di institusi perubatan swasta di Kuala Lumpur. Keputusan kajian tersebut mendapati seramai $73.1 \%$ pesakitnya hadir dengan simptom batuk dan $54 \%$ daripada mereka telah menghantar spesimen kahak ke makmal perubatan untuk dianalisis (Nissapatorn et al. 2007).

Simptom dan jenis spesimen dalam kajian ini menunjukkan bahawa majoriti pesakit yang hadir di PPUKM adalah disebabkan oleh jangkitan tibi pulmonari. Kajian kes yang dijalankan di Universiti Sains Malaysia pada 2004, mendapati bahawa batuk merupakan simptom klasik bagi pesakit tibi pulmonari. Hasil pemerhatian tersebut mendapati $92 \%(218 / 203)$ pesakit yang hadir dengan simptom batuk adalah pesakit tibi pulmonari (Mutallif 2004). Pemerhatian sama turut diperoleh melalui satu kajian yang dijalankan oleh Nissapatorn et al. (2005) yang mendapati jangkitan pulmonari merupakan jangkitan utama dalam kalangan populasi sampelnya.

Dalam kebanyakan kajian kes yang dilakukan, kes tibi ekstrapulmonari merupakan kes-kes yang agak terpencil jika dibandingkan dengan kes tibi pulmonari (Mutallif
2004; Nik et al. 2011; Nissapatorn et al. 2005). Pemerhatian ini adalah selari dengan keputusan kajian yang mendapati hanya $20 \%$ daripada pesakit didiagnosis dengan jangkitan tibi ekstrapulmonari.

Dalam kajian yang dilakukan, terdapat dua orang pesakit yang dikenal pasti sebagai kes tibi berulang. Kes tibi berulang boleh didefinisikan sebagai pesakit yang telah menerima rawatan tibi dengan sempurna dan disahkan sembuh tetapi menjadi aktif semula dengan kahak positif atau berdasarkan pemeriksaan bakteriologi, histologi atau klinikal-radiologi. Pesakit ini didiagnosis semula sebagai tibi dan dikira sebagai episod tibi yang baharu. Regimen rawatan bagi kes tibi berulang atau kes terhenti rawatan atau kes gagal rawatan akan ditentukan oleh pakar perubatan berdasarkan kepada keputusan ujian kultur dan sensitiviti kahak. Kes tibi berulang boleh berlaku disebabkan oleh beberapa faktor seperti kegagalan rawatan ketika jangkitan pertama, jangkitan strains M. tuberculosis yang berbeza dan ketahanan sistem keimunan yang sangat rendah. Kajian yang dilakukan di Kelantan mendapati, jangkitan HIV merupakan salah satu faktor kegagalan rawatan tuberkulosis (Nik et al. 2011).

Perkembangan bioteknologi hari ini telah memberikan banyak pilihan kepada industri perubatan dalam memilih kaedah terbaik dalam proses diagnosis penyakit. Dalam ujian kerentanan anti-TB ke atas $M$. tuberculosis, penggunaan medium merupakan kaedah klasik yang telah lama diguna pakai. Namun begitu, atas desakan beberapa faktor seperti pemendekan masa diagnosis dan pengurusan tenaga kerja telah mendorong penggunaan teknik baru yang lebih praktikal. Kajian mendapati, prosedur plat МYСОТВ mengambil masa $26 \mathrm{~min} 30 \mathrm{~s}$ bagi menyempurnakan ujian sensitiviti bagi satu sampel. Di samping itu, plat МҮСОТВ dapat memberikan nilai MIC bagi 13 jenis bahan antimikrob berbeza sesuatu sampel. Berbeza dengan prosedur BACTEC MGIT 960, keseluruhan prosedur memerlukan 40 min $30 \mathrm{~s}$ bagi menyempurnakan ujian sensitiviti bagi satu sampel. Walau bagaimanpun, maklumat terhad kepada tahap sensitiviti pencilan sampel pada satu kepekatan bagi satu jenis antimikrob sahaja. Kim (2005), menyarankan pelaksanaan teknik diagnostik yang dapat memberikan hasil yang lebih cepat, sesuai dengan perkembagan semasa. Ini adalah penting bagi memastikan pihak makmal perubatan mampu menyokong keperluan semasa dalam

JADUAL 5. Keputusan MIC daripada ujian plat MYCOTB

\begin{tabular}{cccc}
\hline Agen antimikrob & \multicolumn{3}{c}{ Kepekatan Plat MYCOTB $(\mu \mathrm{g} / \mathrm{mL})$} \\
\hline Streptomycin & $<0.25$ & 0.25 & 1 \\
Bil. pencilan & 3 & 23 & 24 \\
Isoniazid & $<0.03$ & 0.06 & \\
Bil. pencilan & 27 & 13 & \\
Rifampicin & $<0.12$ & & \\
Bil. pencilan & 40 & 0.6 & 1.2 \\
Ethambutol & 0.3 & 0 & 39 \\
Bil. pencilan & 1 & & \\
\hline
\end{tabular}


JADUAL 6. Keputusan kerentanan bagi 40 pencilan $M$. tuberculosis dengan teknik plat MYCOTB dan BACTEC MGIT 960

\begin{tabular}{ccccc}
\hline Antimikrob & $\begin{array}{c}\text { Kepekatan antimikrob } \\
\text { BACTEC MGIT 960 } \\
(\mu \mathrm{g} / \mathrm{mL})\end{array}$ & $\begin{array}{c}\text { Keputusan plat } \\
\text { MYCOTB }\end{array}$ & $\begin{array}{c}\text { Bil. pencilan rintang } \\
\text { dengan teknik } \\
\text { BACTEC MGIT 960 }\end{array}$ & $\begin{array}{c}\text { Bil. pencilan rentan } \\
\text { dengan teknik } \\
\text { BACTEC MGIT 960 }\end{array}$ \\
\hline Streptomycin & 1.0 & Rintang & 0 & 0 \\
Isoniazid & 0.1 & Sensitif & 0 & 40 \\
& \multirow{2}{*}{1.0} & Rintang & 0 & 0 \\
Rifampicin & Sensitif & 0 & 0 \\
& \multirow{2}{*}{5.0} & Rintang & 0 & 40 \\
Ethambutol & Sensitif & 0 & 0 \\
& & Rintang & 0 & 40 \\
\hline
\end{tabular}

bidang perubatan terutamanya dalam kawalan jangkitan penyakit berjangkit.

Bahan antimikrob yang terdapat pada plat MYCOTB telah dihablurkan dan tiada sebarang penyediaan awal perlu dilakukan sebelum menjalankan ujian. Berbeza dengan prosedur BACTEC MGIT 960, beberapa penyediaan awal perlu dilakukan. Penyediaan medium pengkaya S.I.R.E BACTEC yang tidak teliti bukan sahaja akan meningkatkan risiko kontaminasi, malahan meningkatkan kos ujian. Satu kajian yang dijalankan di Pakistan pada tahun 2010, mendapati kadar kontaminasi adalah tinggi dalam penggunaan teknik BACTEC MGIT 960. Ini adalah disebabkan oleh faktor tenaga kerja yang kurang mahir dan penyediaan medium yang tidak teliti ketika menjalankan ujian (Satti et al. 2010).

Daripada aspek kos setiap ujian, penggunaan teknik plat МYСОТВ lebih menjimatkan jika dibandingkan BACTEC MGIT 960. Tambahan pula teknik plat MYCOTB tidak memerlukan mesin khas dalam prosedurnya. Kos yang perlu ditanggung oleh pihak makmal perubatan bagi perolehan mesin BACTEC MGIT 960 adalah sekitar RM300,000.

Median masa bagi menjalankan ujian sensitiviti dengan plat MYCOTB dengan sempurna adalah sepuluh hari manakala BACTEC MGIT 960 median bagi setiap sampel adalah 14 hari. Dalam masa sepuluh hari plat MYCOTB bukan sahaja dapat memberikan keputusan bahan antimikrob barisan pertama malahan beberapa nilai MIC bahan antimikrob barisan kedua secara serentak. Sekiranya terdapat sebarang pencilan yang dikenal pasti sebagai MDR-TB teknik plat MYCOTB dapat memberikan keputusan yang cepat dan sangat bermakna bagi perawatan pesakit. Ini dapat memendekkan turn around time sesuatu ujian.

Sensitiviti merujuk kepada kebolehan sesuatu ujian untuk memberikan keputusan yang tepat atau sama dengan keputusan piawai. Dalam kajian ini, keputusan sensitiviti yang dicerap melalui teknik plat MYCOTB telah dibandingkan dengan hasil piawai iaitu BACTEC MGIT. Pemerhatian mendapati nilai sensitiviti plat МYСОТВ adalah $100 \%$. Pemerhatian yang sama telah diperoleh melalui kajian yang dilakukan oleh Hall et al. (2012) yang mendapati teknik plat MYCOTB memberikan nilai sensitiviti 94\% hingga $100 \%$.

Makmal kesihatan memainkan peranan yang sangat penting dalam mengenal pasti jangkitan tuberkulosis dan memantau keberkesanan rawatan. Keputusan yang diperoleh bukan sahaja menyokong diagnosis pakar perubatan malahan dapat membantu mereka mendapatkan gambaran sebenar berkaitan epidiomiologi sesuatu jangkitan penyakit. Di samping itu, sebarang pembentukan strain yang rintang terhadap ubat-ubatan dapat dikenal pasti dengan lebih cepat. Maklumat ini boleh diperoleh melalui nilai MIC bagi setiap bahan antimikrob yang telah dicerap melalui plat мYCOTB. Keputusan kajian mendapati kesemua pesakit di PPUKM mempunyai nilai MIC yang lebih rendah berbanding nilai kepekatan bahan antimikrob yang telah ditetapkan oleh BACTEC MGIT 960. Ini memberikan gambaran yang baik kerana kebanyakan strain adalah sangat rentan terhadap dadah antituberkulosis dan pelaksanaan pengurusan dan perawatan pesakit tibi di PPUKM adalah berkesan.

\section{KESIMPULAN}

Dalam kajian yang dijalankan, ujian sensitiviti dengan menggunakan plat MYCOTB mampu memberikan sensitiviti $100 \%$ setanding teknik medium kultur yang diaplikasi dalam sistem BACTEC MGIT 960. Melalui kajian ini, dapat dilihat juga bahawa plat MYCOTB merupakan teknik yang boleh mengurangkan kadar kontaminasi, memendekkan tempoh diagnosis malahan dapat memberikan maklumat yang sangat berguna kepada pengamal perubatan. Maklumat yang diperoleh bukan sahaja membantu dalam perawatan pesakit malahan dapat digunakan sebagai maklumat sokongan dalam pengemaskinian panduan rawatan tibi pada masa hadapan.

\section{RUJUKAN}

CDC 2013. Chapter 2. Transmission and pathogenesis of tuberculosis. In Core Curriculum on Tuberculosis: What the Clinician Should Know. 6th ed. Centers for Disease Control and Prevention. National Center for HIV/AIDS, Viral 
Hepatitis, STD, and TB Prevention. Division of Tuberculosis Elimination.

Chang, C. \& Esterman, A. 2007. Diagnostic delay among pulmonary tuberculosis patients in Sarawak, Malaysia: A cross-sectional study. Rural Remote Health 7(2): 667.

Dony, J.F., Ahmad, J. \& Khen Tiong, Y. 2004. Epidemiology of tuberculosis and leprosy, Sabah, Malaysia. Tuberculosis 84(1): 8-18.

Hall, L., Jude, K.P., Clark, S.L., Dionne, K., Merson, R., Boyer, A., Parrish, N.M. \& Wengenack, N.L. 2012. Evaluation of the sensititre mycotb plate for susceptibility testing of the Mycobacterium tuberculosis complex against first-and second-line agents. Journal of Clinical Microbiology 50(11): 3732-3734.

Hooi, L. 1994. Case finding for pulmonary tuberculosis in Penang. Medical Journal of Malaysia 49: 223-230.

Kementerian Kesihatan Malaysia (KKM). 2013. Malaysia: Achieving the Millennium Development Goals (MDG).

Kementerian Kesihatan Malaysia (KKM). 2000. Annual Report: National Tuberculosis/Leprosy Control Program.

Kim, S. 2005. Drug-susceptibility testing in tuberculosis: Methods and reliability of results. European Respiratory Journal 25(3): 564-569.

Krejcie, R.V.\& Morgan, D.W. 1970. Determining sample size for research activities. Edu. Psycho. Measurement 30: 607-610.

Mokhtar, K.S., Rahman, N., Shariff, N. \& Nor, W.A.W.M. 2012. Tuberculosis in Malaysia: A study on the level of societal awareness and stigma. Journal of Humanities and Social Science 1: 59-64.

Mutallif, A.R. 2004. Significance of symptoms and investigations in tuberculosis case finding. Malaysian Journal of Pharmaceutical Sciences 2(2): 29-30.

Nantha, S. 2014. A review of tuberculosis research in Malaysia. Med. J. Malaysia 69: 88-102.

Nik, N.R., Mohd, N.S., Wan, M.Z., Sharina, D. \& Nik Rosmawati, N.H. 2011. Factors associated with unsuccessful treatment outcome of pulmonary tuberculosis in Kota Bharu, Kelantan. Malaysian Journal of Public Health Medicine 11(1): 6-15.

Nissapatorn, V., Kuppusamy, I., Sim, B., Quek, K. \& Khairul Anuar, A. 2005. Tuberculosis in HIV/AIDS patients: A Malaysian experience. Southeast Asian Journal of Tropical Medicine and Public Health 36(4): 946-953.
Nissapatorn, V.,Lee, C. \& Khairul,A. 2001. Impact of pulmonary opportunistic infections among AIDS patients in General Hospital Kuala Lumpur, Kuala Lumpur, 2001.Trop. Biomed. 18(2): 117-121.

Nissapatorn, V., Lim, Y., Jamaiah, I., Man Chin, H., Ilyana, M., Nonaziah, M., Siti Hasifah, A. \& Kuppusamy, I. 2007. Tuberculosis in Malaysia: A continuing surge. Southeast Asian Journal of Tropical Medicine and Public Health 38(231): 201-220.

Russell,D.G. 2011. Mycobacterium tuberculosis and the intimate discourse of a chronic infection. Immunol.Rev. 240: 252-268.

Satti, L., Ikram, A., Abbasi, S., Butt, T., Malik, N. \& Mirza, I.A. 2010. Evaluation of Bactec MGIT 960 system for recovery of Mycobacterium tuberculosis complex in Pakistan. Malay. J. Microbiol 6: 203-208.

Waaler, H.T. 2002. Tuberculosis and poverty. International Journal of Tubercle Lung Disease 6: 745-746.

WHO. 1974. WHO Expert Committee on Tuberculosis: 9th Report, Laporan Teknik Siri 552, Geneva, Switzerland.

Noraziah Mohamad Zin* \& Nur Hidayah Masod

Program Sains Bioperubatan

Pusat Sains Kesihatan dan Gunaan

Universiti Kebangsaan Malaysia

50300 Kuala Lumpur, Wilayah Persekutuan

Malaysia

Alfizah Hanafiah

Jabatan Mikrobiologi dan Immunologi Perubatan

Fakulti Perubatan, Universiti Kebangsaan Malaysia

Jalan Yaacob Latif, Bandar Tun Razak

56000 Cheras, Kuala Lumpur, Wilayah Persekutuan

Malaysia

*Pengarang untuk surat-menyurat; email: noraziah.zin@ukm. edu.my

Diserahkan: 11 Mac 2016

Diterima: 6 Oktober 2017 